\title{
Sediment structure at the equatorial mid-atlantic ridge constrained by seafloor admittance using data from the PI-LAB experiment
}

\author{
Utpal Saikia $^{1}$ - Catherine Rychert ${ }^{1}$ - Nicholas Harmon ${ }^{1}$. J. M. Kendall ${ }^{2}$
}

Received: 4 October 2019 / Accepted: 26 January 2020 / Published online: 15 February 2020

(c) The Author(s) 2020

\begin{abstract}
Well-constrained marine sediment characteristics (sediment thickness and shear wave velocity) are important not only for the study of climate over geologic times scales but also for correcting and accounting for its presence in seismic data used to investigate deeper structures. We use data from the PI-LAB (Passive Imaging of the Lithosphere Asthenosphere Boundary) experiment, which consisted of 39 broadband ocean bottom seismometers deployed at the Equatorial Mid-Atlantic Ridge near the Chain fracture zone covering 0-80 Myr old seafloor. We compute admittance between the pressure to the vertical displacement at the seafloor at frequencies between 0.1 and $0.2 \mathrm{~Hz}$ for microseism-generated Rayleigh waves for 18 stations where data quality is good to determine the sediment thickness and shear wave velocity. We find a general trend of increasing sediment thickness with the seafloor ages, as expected with sediment thicknesses that range from 10-450 m and, shear wave velocities that range from $0.05-0.34 \mathrm{~km} / \mathrm{s}$. We find sediment thickness varies almost uniformly across both sides of the ridge, and it indicates that both sides experienced a similar sedimentation process. Our results are in good agreement with the global sediment model that is based on drilling cores and active source experiments, but thinner by up to $50 \mathrm{~m}$ at several stations on seafloor older than $25 \mathrm{My}$. Overlap of the $95 \%$ confidence regions between admittance and Ps estimates for thickness and shear velocity is found at 15 stations where we have both Ps and admittance estimates. It suggests that both methods yield accurate estimates for sediment thickness. In addition, our admittance result extends the lateral resolution of sediment characteristics to stations that were not previously resolved by Ps.
\end{abstract}

Keywords Ocean bottom seismometers $\cdot$ Admittance function $\cdot$ Sediment properties $\cdot$ Shear wave velocity

\section{Introduction}

Broadband Ocean Bottom Seismometers (OBS) are deployed on the seafloor often coupled to the solid earth on marine sediments. These deployments provide an opportunity to estimate the properties of the marine sediments, such as their average thickness and seismic velocities using a variety of techniques using both body (Harmon et al. 2007; Agius et al. 2018; Rychert et al. 2018) and surface waves (Ruan et al. 2014; Lewis et al. 1998; Bell et al. 2015). These estimates are useful to enhance the further analysis of seismic phases (Harmon et al. 2007) to prevent mapping seismic

Utpal Saikia

ngriutpal@gmail.com

1 Ocean and Earth Science, University of Southampton, Southampton University, Southampton, UK

2 School of Earth Sciences, University of Bristol, Bristol, UK delays associated with sediments into deeper structure and can also provide information about the sedimentation rates which are important for climate estimates over geological timescales (Agius et al. 2018). The passive seismic methods also complement traditional methods used to determine the shear and compressional properties, including for instance, active source seismic or drill core analyses (Dorman and Jacbson 1981; Berge et al. 1991; Essen et al. 1998).

In this paper, we use the spectral ratio between the pressure and vertical component of the OBS for microseismgenerated Rayleigh waves propagating past the station to estimate sediment properties beneath the seismic station. This method differs from the compliance method, which also uses the spectral ratio of the pressure and vertical components, but at lower frequencies, due to loading by ocean infragravity waves at lower frequencies $\sim 0.001-0.02 \mathrm{~Hz}$ (Crawford et al. 1991). We present results from the Passive Imaging of the Lithosphere-Asthenosphere Boundary (PI$\mathrm{LAB}$ ) experiment deployed on and around the equatorial 
Mid Atlantic Ridge (Harmon et al. 2018; Agius et al. 2018). We compare our results to estimates for sediment properties using Ps converted waves from the same data set and the global compilation of sediment thickness (Straume et al. 2019) and then examine the trend with the age of the seafloor or sedimentation rate and also the velocity-depth relationship of the sediment.

\section{Data and methodology}

In the present study, we use data from the PI-LAB experiment, which includes 39, 3-component broadband Ocean Bottom Seismometers (OBS) each equipped with a differential pressure gauge (DPG), deployed from March 2016 to March 2017 (Fig. 1). We use the vertical component and DPG data for this study. Although, initially 39 stations were installed, 2 (I01D and I36D) were not recovered, 15 had technical errors caused by lack of recording of one or more channels, contamination from frequent leveling, flooded sensor and/or short duration of recording (weeks to a few months). The remaining 22 stations recorded data on all four components for at least 11 months, four of which still had low coherence $(<0.8)$ either owing to noise or higher mode contamination (Table 2 ). We preprocess the data by down sampling to $1 \mathrm{~Hz}$, removing the instrument response between 0.005 and $0.5 \mathrm{~Hz}$. The tilt noise is removed from the vertical component before calculating the pressure-tovertical displacement transfer function (Crawford and Webb 2000).

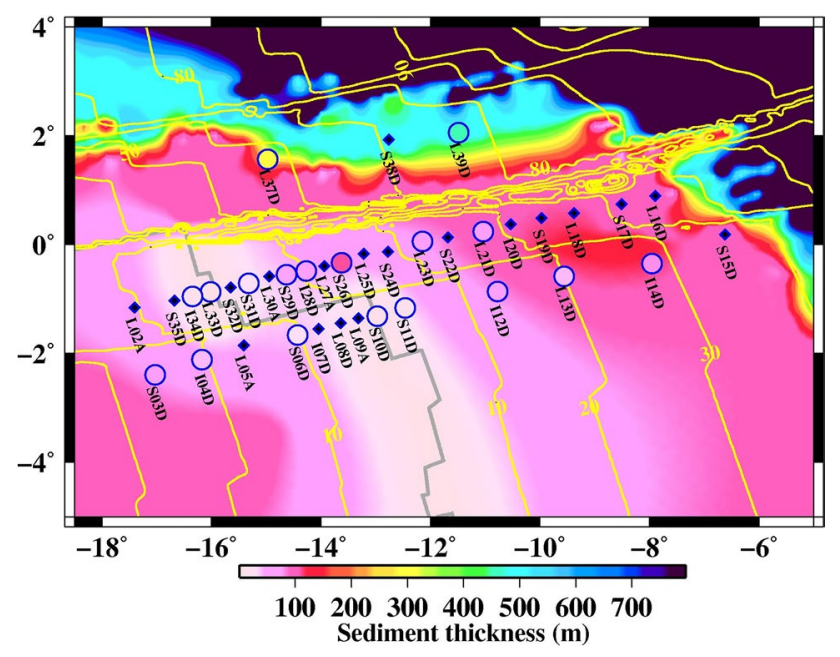

Fig. 1 Comparison of estimated sediment thickness with the global sediment thickness model. Seafloor age is shown as yellow contours (Muller et al. 2008). Estimated sediment thickness (colours within blue circles) is overlaid on the global sediment thickness model (background colour). The filled blue color diamonds show the seismic locations where we not able to measure sediment thickness. Grey line shows the location of the Mid-Atlantic Ridge plate boundary
Seafloor admittance can be described by the complex transfer function $n(\omega)$ in frequency $\omega$ between the vertical displacement $\mathrm{u}_{\mathrm{z}}(\omega)$ and the differential pressure $\Delta \mathrm{P}(\omega)$ at the seafloor (Ruan et al. 2014; Bell et al. 2015).

$\mathrm{n}(\omega)=\frac{\mathrm{u}_{\mathrm{z}}(\omega)}{\Delta \mathrm{P}(\omega)}$

The vertical displacement and normal stress for the predicted admittance function was estimated based on the surface wave dispersion code from Computational Programs in Seismology (Herrmann 1978) at frequencies from 0.02 to $0.2 \mathrm{~Hz}$.

To avoid bias in the presence of noise, the transfer function is calculated from the following formula for each day long record of the data:

$\mathrm{n}(\omega)=\frac{<\mathrm{u}_{\mathrm{z}}(\omega) \cdot \Delta \mathrm{P} *(\omega)>}{<\Delta \mathrm{P}(\omega) \cdot \Delta \mathrm{P} *(\omega)>}$

where the angle brackets indicate averaging over a number of individual time windows or samples, and the asterisk indicates the complex conjugate. We use a moving 2048s time window with $50 \%$ overlap to evaluate (2) using Welch's method. We determine the coherence $\gamma 2(\omega)$ of $n(\omega)$ using the same Welch's method:

$\gamma^{2}(\omega)=\frac{\left\lceil\left.\left\langle u_{z}(\omega) \cdot \Delta P *(\omega)\right\rangle\right|^{2}\right.}{\left\langle u_{z}(\omega) \cdot u_{z} *(\omega)\right\rangle\langle\Delta P(\omega) \cdot \Delta P *(\omega)\rangle}$

Days where the average coherence was $>0.8$ between 0.1 and $0.2 \mathrm{~Hz}$ were averaged to generate $\mathrm{n}(\omega)$ used in the study below.

We invert the transfer function to constrain the sediment structure using a grid search method over sediment thickness and shear velocity. We fit the data in the frequency range between ( 0.1 and 0.2$) \mathrm{Hz}$ where seafloor deformation is dominated by Rayleigh waves (Webb et al. 1991). The grid search method varies sediment thickness (h) with an increment of $0.01 \mathrm{~km}$ from 0.01 to $0.40 \mathrm{~km}$ thickness and shear wave speed $\left(\mathrm{V}_{\mathrm{s}}\right)$ with an increment of $0.02 \mathrm{~km} / \mathrm{s}$ from 0.01 to $0.4 \mathrm{~km} / \mathrm{s}$ to minimize the difference between the predicted and observed admittance function between 0.1 and $0.2 \mathrm{~Hz}$. For one station (L39D), where we did not find a satisfactory fit, we increased the grid search area ( $\mathrm{v}_{\mathrm{s}}$ up to $0.5 \mathrm{~km} / \mathrm{s}$ and $\mathrm{h}$ is up to $0.6 \mathrm{~km}$ ). We allow for a pre-factor that accounts for imperfect calibration of the pressure records and the vertical relative to the predicted models. The pre-factor represents the shift required to align the synthetic admittance curve to the data in the frequency range between 0.02 and $0.1 \mathrm{~Hz}$ where the pressure record is only sensitive to the water column, i.e., avoiding higher frequencies where we are modelling sediment characteristics. The fit result is demonstrated at $0.02-0.1 \mathrm{~Hz}$ in Fig. 2. The pre-factor provides 

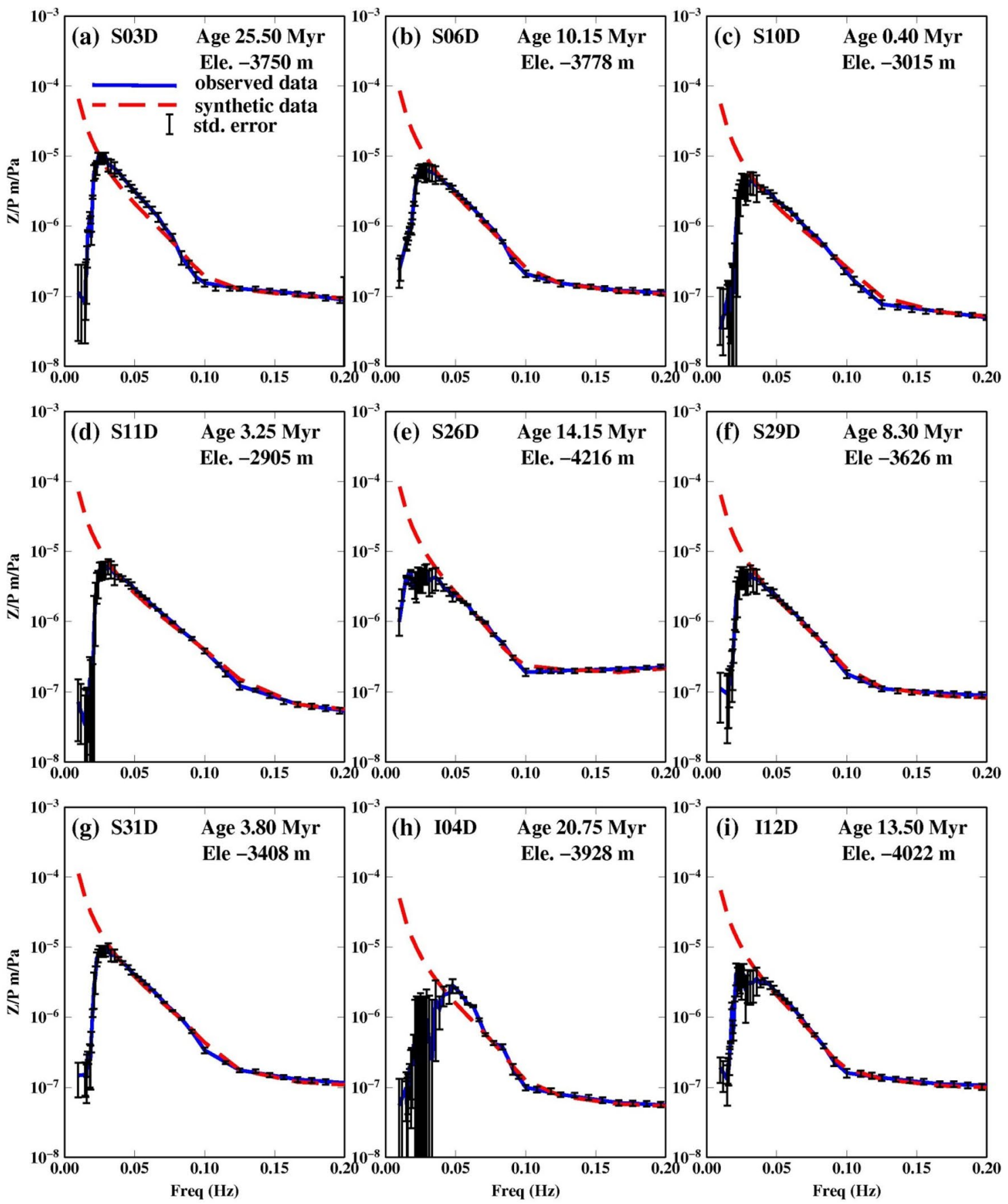

Fig. 2 Data fits from inversion results at each station. Water depths and seafloor ages are reported in the top right hand corner. The observed admittance functions are shown as blue lines and the best fit synthetics are shown as red, dashed lines. We only determine sedi- ment properties using frequencies $>0.1 \mathrm{~Hz}$, but show lower frequencies $(0.02-0.1 \mathrm{~Hz})$ which are only sensitive to the water column to demonstrate the good calibration achieved with the pre-factor the gain correction for the DPG, and is equivalent to the result of approaches that have used pressure-to-acceleration ratios (Zha and Webb 2016) as has been noted previously for admittance studies (Ruan et al. 2014). The pre-factor is the DPG gain factor assuming there are no gain issues with the seismometer. The water depth at each station is fixed to observed value from the multibeam bathymetry collected during the seismic deployment.

We use a seismic velocity model for the crust and uppermost mantle obtained from Ruan et al. (2014) with minor modifications made in-terms of layer thickness and velocities (Table 1). P-wave velocity in the sediment layer is fixed at 

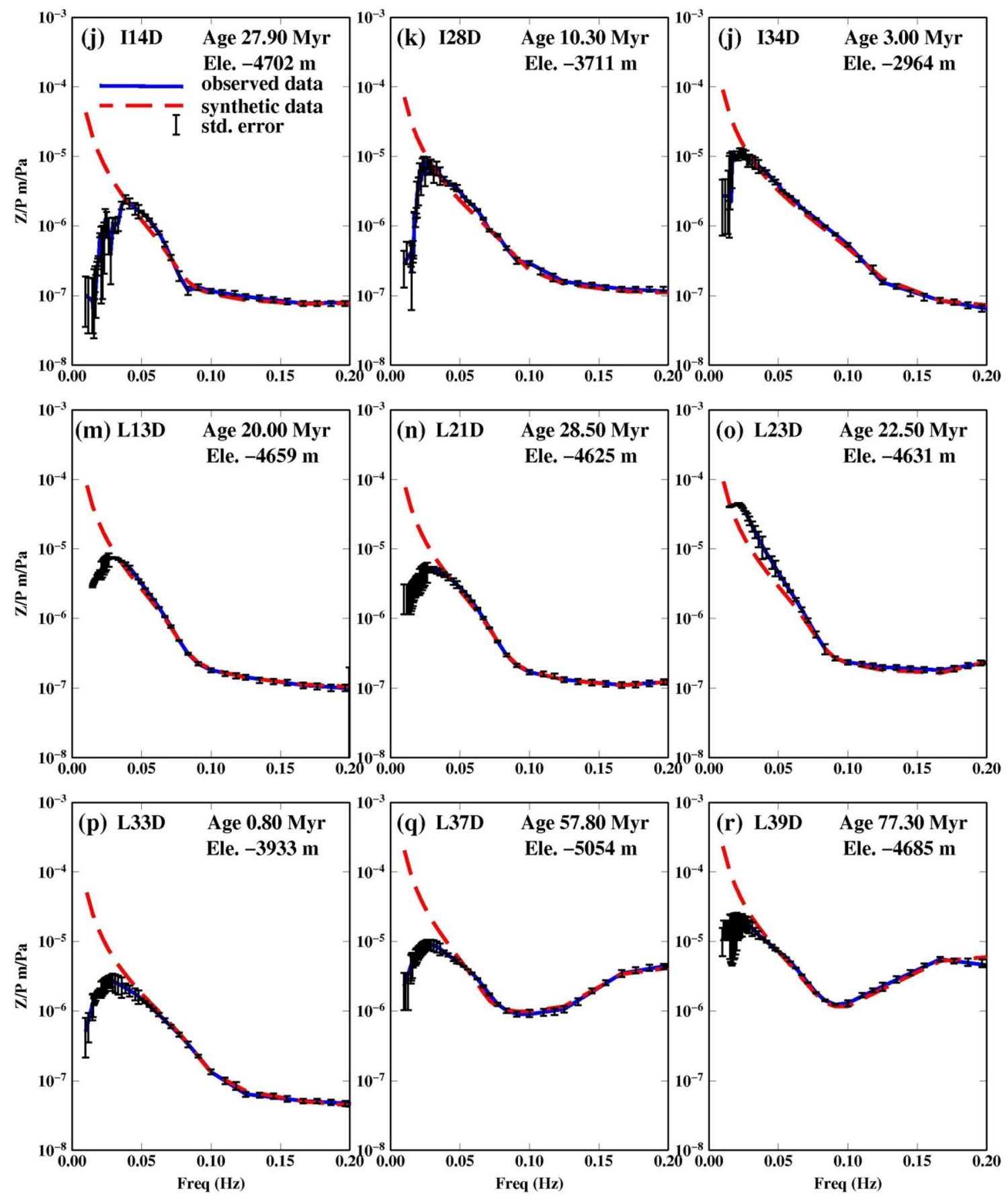

Fig. 2 (continued)

Table 1 Assumes model parameters, altered from Ruan et al. (2014)

\begin{tabular}{lllll}
\hline Layer & Thickness $(\mathrm{km})$ & $\rho\left(\mathrm{g} / \mathrm{cm}^{3}\right)$ & $v_{p}(\mathrm{~km} / \mathrm{s})$ & $v_{s}(\mathrm{~km} / \mathrm{s})$ \\
\hline Water & Local, fixed & 1.03 & 1.53 & 0.0 \\
Sediment & Variable & 2.00 & 1.75 & - \\
Upper crust & 3 & 2.40 & 5.10 & 2.65 \\
Lower crust & 6 & 3.15 & 6.90 & 3.95 \\
Uppermost mantle & 20 & 4.30 & 7.90 & 3.35 \\
\hline
\end{tabular}

$1.75 \mathrm{~km} / \mathrm{s}$, and density is set to $2000 \mathrm{~kg} / \mathrm{m}^{3}$, although testing with a range of other values $(1.65 \mathrm{~km} / \mathrm{s}$ and $1.85 \mathrm{~km} / \mathrm{s})$ indicated that they have little effect on the final result. To study the effect of initial crustal and upper most mantle velocity on the inversion results, we also performed inversion using Crust 1.0 (Laske et al. 2013) and the velocity model derived from surface wave analysis of the study region (Rychert et al. 
2017). Testing with these other velocity models indicated they have little effect on the final results.

For each OBS, the $95 \%$ confidence region is determined by a grid search and defined by the following equation (Draper and Smith 1998).

$S(\theta)=S(\hat{\theta})\left[1+\frac{p}{n-p} F^{\prime}(p, n-p, 1-\alpha)\right]$

where $S(\hat{\theta})$ defines the best fit variance, $\mathrm{p}$ is the number of parameters $(\mathrm{p}=2), \mathrm{n}$ is the number of observations $(\mathrm{n}=11$, the number of frequencies between 0.1 and $0.2 \mathrm{~Hz}$ ), and $\alpha$ defines the confidence of $95 \%$ interval. $F^{\prime}(p, n-p, 1-\alpha)$ is the $\mathrm{F}$ distribution. We note that in calculating our confidence regions our choice of the number of observations is conservative, and could possibly be smaller than previous studies (Bell et al. 2015; Ruan et al. 2014). For instance, we could have chosen the number of observations as the number of frequencies multiplied by the number of admittance curves averaged in the stack.

To check the conformity, we compare the present result with the global sediment thickness (Straume et al. 2019) and earlier published result using P-to-s (Ps) conversions (Agius et al. 2018). We checked whether present result overlaps the $95 \%$ confidence region of the Ps result using previously reported dt and $1 \sigma$ error bars (Agius et al. 2018), and the following equation to estimate sediment thickness:

$d t=h\left(\sqrt{\left(1 / V_{s}\right)^{2}-u^{2}}-\sqrt{\left(1 / V_{p}\right)^{2}-u^{2}}\right)$

where dt, $h, u, v_{p}$ and $v_{s}$ represent the delay time, sediment thickness, horizontal slowness, P- and S-wave velocity, respectively. We assumed an average slowness (u) value of $0.60 \mathrm{~s} / \mathrm{km}$ and an average $v_{p}$ value of $1.75 \mathrm{~km} / \mathrm{s}$, and varied shear wave velocity from 0.01 to $0.4 \mathrm{~km} / \mathrm{s}$ with an increment of $0.01 \mathrm{~km} / \mathrm{s}$.

\section{Results}

We report results for 18 stations with good coherence $(>0.8)$ (Table 2). The admittance function pattern varies as it moves away from the ridge, becoming more U-shaped and concave upwards as the seafloor age increases (Fig. 2). The fit to the data for the selected 18 stations is shown in Fig. 2. The average estimated sediment thickness, shear wave velocity and corresponding error of the 18 stations are listed in Table 2 as well as the DPG gain factors determined from the grid search. The best fit from the grid search results are shown in Fig. 3 along with the 95\% confidence region. The error surfaces of stations S26D, L37D and L39D have a different trend than the rest of the stations, as expected, reflecting the larger trade-off between velocity and thickness in locations with thicker sediment (Fig. 3). The effect of using different crustal velocity models on the inversion results is shown in Fig. 4.

We present the inversion results for each station in terms of seafloor ages (Fig. 5). For 0-10 My old seafloor estimated sediment thickness varies from 10 to $45 \mathrm{~m}$ and it increases with the seafloor ages (Fig. 4). The maximum thickness is detected at S29D station (seafloor age 8.30 Myr), while the minimum $(10 \mathrm{~m}$ ) is found at stations S10D and L33D (seafloor age $0.41-0.80 \mathrm{Myr}$ ). For 10-20 My old seafloor, the maximum sediment thickness is detected at S26D station of about $120 \mathrm{~m}$, thicker than the surrounding stations, which range from 30-60 m (Fig. 4). For 20-40 Myr old seafloor, the inferred sediment thickness is $40-80 \mathrm{~m}$ (Fig. 4). For 41-77.5 Myr old seafloor we find thicknesses of 300-450 m.

\section{Discussion}

Comparison of the $95 \%$ confidence regions of the admittance study presented here and the $1 \sigma$ confidence regions of the Ps converted phase study of Agius et al. (2018) is shown in Fig. 3. The confidence regions overlap in 15 out of 16 stations where both techniques were used, even if the best fitting parameters estimated between the two studies do not necessarily lie within each other's confidence limits. Typically, our best-fitting thickness is similar to that from Ps, but our velocity result is slower. However, the Ps study assumed the velocity-thickness relationship determined by Ruan et al. (2014) for Cascadia. This could suggest that sediment properties in the Atlantic are not the same as Cascadia. Both methods have good sensitivity to the sediment thickness at low thickness $(<\sim 200 \mathrm{~m})$, but relatively poor sensitivity to shear velocity, evidenced by the elongation of the confidence regions along the shear velocity axis. The two confidence regions did not overlap in one case, site S26D, where the admittance method indicated $110 \mathrm{~m}$ sediment thickness and the Ps delay indicated 35-50 m (Aguis et al. 2018). In this region, it may be that the Ps phase is sensitive to layering within the sediment, thus giving an artificially thin result. In other studies, Ps has been shown to be consistent with estimates from compliance studies in thicker sediments up to $1.5 \mathrm{~km}$ in the Pacific Hawaii (Doran and Laske 2019). Consistency between the methods may depend on the structure and type of the sedimentation.

Our trends in sediment thickness with age are generally consistent with the notion that oceanic sediments thicken with increasing age of the lithosphere (Olson et al. 2016; Sclater 2003) (Fig. 5). The estimated sediment thickness varies from 10-20 $\mathrm{m}$ at the ridge axis and reaches up-to $400-450 \mathrm{~m}$ on the seafloor older than $70 \mathrm{Myr}$. At $>70$ My seafloor the greater thickness likely reflects both the 
Table 2 PI-LAB stations latitude, longitude, elevation, seafloor age, average sediment thickness $(\mathrm{h})$, average shear wave velocity ( $\left.\mathrm{v}_{\mathrm{s}}\right)$ and the corresponding error

\begin{tabular}{|c|c|c|c|c|c|c|c|c|c|}
\hline Station & Long. $\left({ }^{\circ}\right)$ & Lat. $\left({ }^{\circ}\right)$ & Ele. (m) & Age (Myr) & Thick* (h) (m) & Avg. $v_{\mathrm{s}}(\mathrm{km} / \mathrm{s})$ & Err (h) (m) & $\operatorname{Err} v_{s}(k m / s)$ & DPG gain \\
\hline I04D & -16.1733 & -2.1238 & -3928 & 20.75 & 40 & 0.08 & 10 & 0.18 & 1.22 \\
\hline I07D & -14.0428 & -0.5565 & -3819 & 7.80 & $\mathrm{TE}$ & - & - & - & \\
\hline I12D & -10.7766 & -0.8683 & -4022 & 13.30 & 60 & 0.12 & 20 & 0.07 & 1.26 \\
\hline I14D & -7.9524 & -0.3522 & -4702 & 27.90 & 80 & 0.14 & 10 & 0.02 & 1.31 \\
\hline I20D & -10.5352 & 0.3681 & -4724 & 31.10 & $\mathrm{TE}$ & - & - & - & \\
\hline I28D & -14.2684 & -0.4918 & -3711 & 10.30 & 55 & 0.13 & 21 & 0.15 & 1.54 \\
\hline I34D & -16.3485 & -0.9579 & -2964 & 3.00 & 20 & 0.10 & 12 & 0.16 & 2.13 \\
\hline L02A & -17.4085 & -1.1667 & -3499 & 10.60 & $\mathrm{TE}$ & - & - & - & \\
\hline L05A & -15.4100 & -1.8600 & -4052 & 15.95 & $\mathrm{TE}$ & - & - & - & \\
\hline L08D & -13.6409 & -1.4493 & -3357 & 4.25 & $\mathrm{TE}$ & - & - & - & \\
\hline L09A & -13.3185 & -1.3569 & -3378 & 2.05 & $\mathrm{TE}$ & - & - & - & \\
\hline L13D & -9.5619 & -0.5862 & -4659 & 20.00 & 40 & 0.08 & 10 & 0.03 & 1.71 \\
\hline L16D & -7.8953 & 0.8933 & -4581 & 45.10 & $\mathrm{TE}$ & - & - & - & - \\
\hline L18D & -9.3765 & 0.5769 & -4890 & 36.90 & $\mathrm{LC}$ & - & - & - & - \\
\hline L21D & -11.0380 & 0.2364 & -4625 & 28.40 & 70 & 0.13 & 17 & 0.05 & 1.63 \\
\hline L23D & -12.1478 & 0.0521 & -4631 & 22.50 & 60 & 0.12 & 15 & 0.01 & 2.01 \\
\hline L25D & -13.2230 & -0.1745 & -4207 & 16.60 & $\mathrm{TE}$ & - & - & - & - \\
\hline L27A & -13.9427 & -0.4007 & -3928 & 12.00 & $\mathrm{TE}$ & - & - & - & - \\
\hline L30A & -14.9467 & -0.5880 & -4003 & 6.00 & $\mathrm{TE}$ & - & - & - & - \\
\hline L33D & -16.0152 & -0.8747 & -3933 & 0.80 & 10 & 0.01 & 10 & 0.18 & 1.21 \\
\hline L37D & -14.9718 & 1.5657 & -5054 & 57.80 & 300 & 0.22 & 70 & 0.02 & 1.32 \\
\hline L39D & -11.4904 & 2.0557 & -4685 & 77.00 & 450 & 0.34 & 100 & 0.06 & 1.24 \\
\hline S03D & -17.0315 & -2.4021 & -3750 & 25.35 & 60 & 0.10 & 10 & 0.03 & 2.19 \\
\hline S06D & -14.4298 & -1.6703 & -3778 & 10.15 & 30 & 0.08 & 13 & 0.18 & 2.16 \\
\hline S10D & -12.9697 & -1.3180 & -3015 & 0.41 & 10 & 0.06 & 15 & 0.18 & 1.39 \\
\hline S11D & -12.4602 & -1.1691 & -2905 & 3.25 & 20 & 0.05 & 10 & 0.19 & 1.72 \\
\hline S15D & -6.6228 & 0.1814 & -4927 & 35.70 & $\mathrm{TE}$ & - & - & - & - \\
\hline S19D & -9.9754 & 0.4809 & -4607 & 34.00 & $\mathrm{TE}$ & - & - & - & - \\
\hline S24D & -12.7806 & -0.1383 & -4453 & 18.70 & $\mathrm{TE}$ & - & - & - & - \\
\hline S22D & -11.6799 & 0.1254 & -4352 & 24.95 & $\mathrm{LC}$ & - & - & - & - \\
\hline S24D & -12.7806 & -0.1383 & -4453 & 18.70 & $\mathrm{TE}$ & - & - & - & - \\
\hline S26D & -13.6260 & -0.3434 & -4216 & 14.15 & 110 & 0.19 & 20 & 0.03 & 1.85 \\
\hline S29D & -14.6272 & -0.5597 & -3626 & 8.30 & 45 & 0.08 & 10 & 0.04 & 1.53 \\
\hline S31D & -15.3187 & -0.7141 & -3408 & 3.80 & 30 & 0.06 & 15 & 0.18 & 2.14 \\
\hline S32D & -15.6470 & -0.7968 & -2967 & 1.70 & $\mathrm{TE}$ & - & - & - & - \\
\hline S35D & -16.6798 & -1.0372 & -3773 & 5.50 & $\mathrm{TE}$ & - & - & - & - \\
\hline S38D & -12.7623 & 1.9218 & -4926 & 71.00 & $\mathrm{LC}$ & - & - & - & - \\
\hline
\end{tabular}

Stations labeled TE had a technical error caused by either: lack of recording of one or more channels, contamination from frequent leveling, flooded sensor and/or short duration of recording (weeks to a few months). Stations labeled LC represent stations that recorded data on all four components for at least 11 months, but still had low coherence either owing to noise or higher mode contamination. Stations I01D and I36D were never recovered from the ocean floor

longer sedimentation times and also greater terrigenous sediment input from Africa due to the proximity of the continent and also the prevailing winds (Ruddiman and Janecek 1989). The observed sediment thickness varies almost uniformly across both sides of the ridge and indicates that both sides might have experienced by the same sedimentation process.
We compare our estimated sediment thicknesses as a function of age with the global sediment thickness model (Straume et al. 2019) and an earlier published result (Agius et al. 2018) (Fig. 5). At young ages (<10 Myr), our sediment thicknesses are within the error of the global model. At two stations S10D and L33D near the ridge our sediment estimate is $10 \mathrm{~m}$, and the error bars overlap $0 \mathrm{~km}$, 
(a)

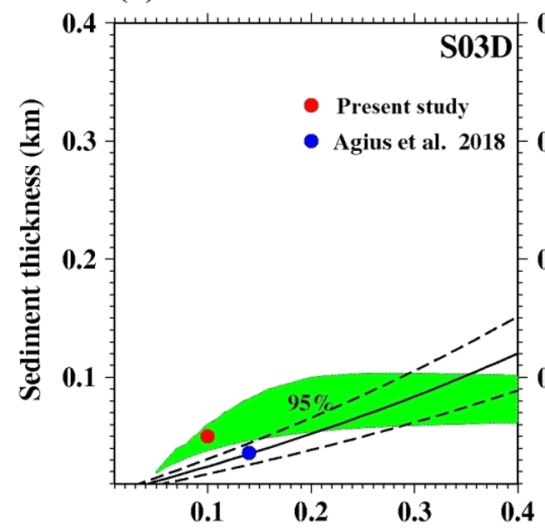

(d)

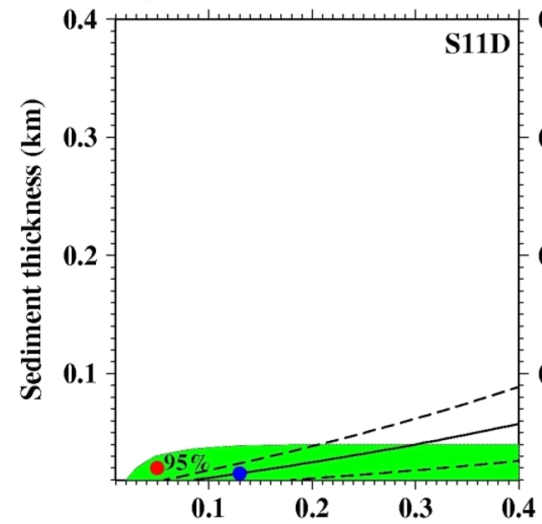

(g)

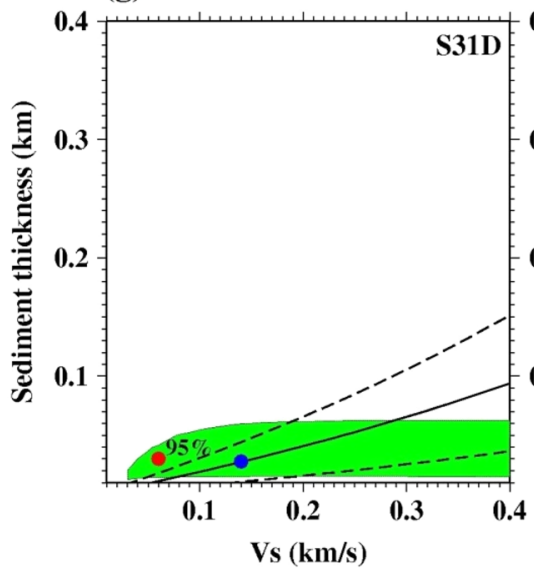

(b)

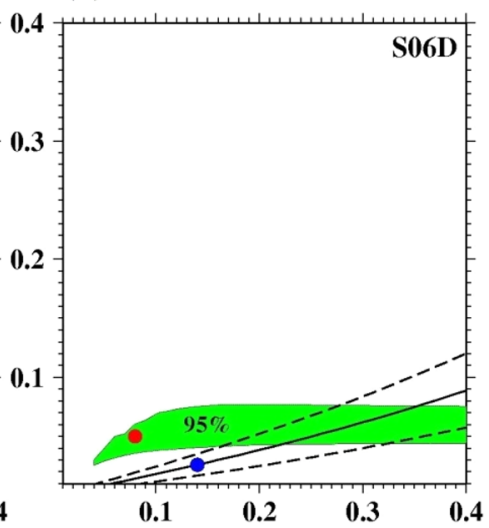

(e)

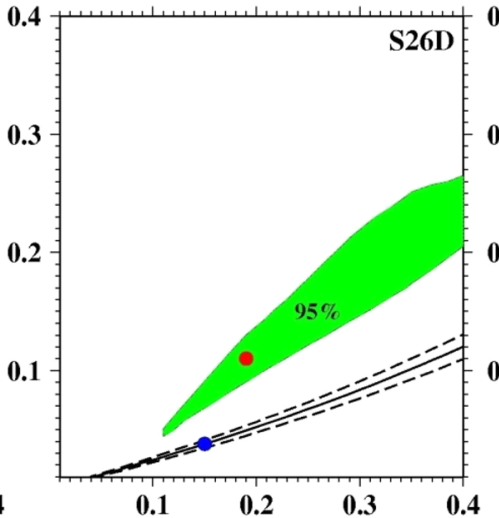

(h)

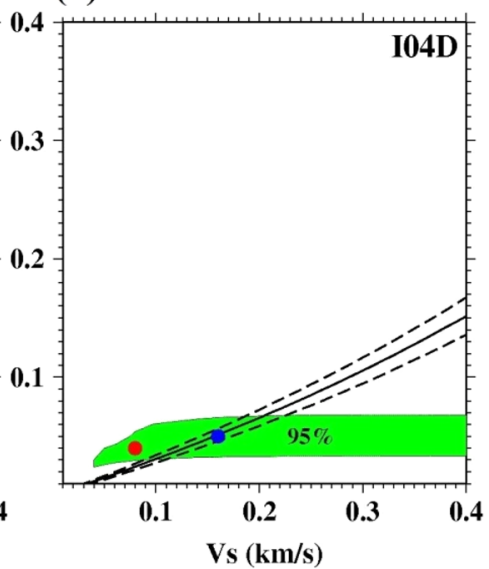

(c)

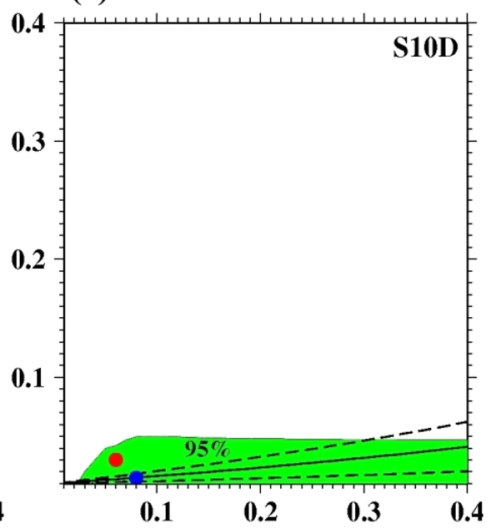

(f)

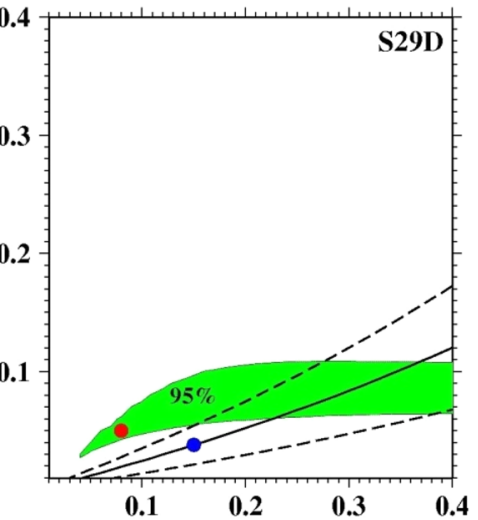

(i)

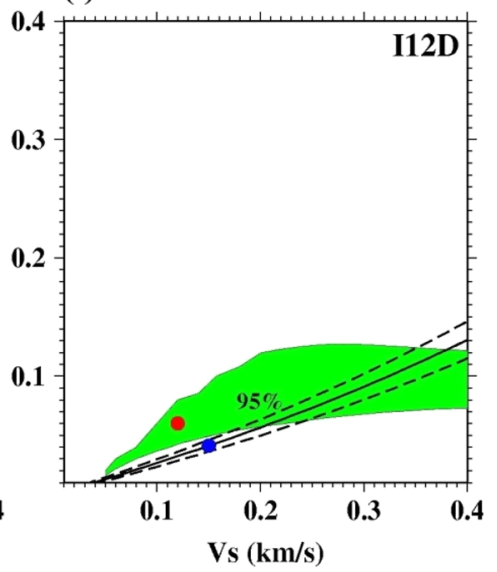

Fig. 3 Grid search results for best fitting sediment thickness and shear wave velocity for each stations. Green area shows the $95 \%$ confidence region of our study, while red circle indicates the optimum value obtained from admittance data. The blue circle indicates the optimum value obtained from the Ps study (Agius et al. 2018). The two dashed line indicate the region of acceptable value from Ps delay time with $1 \sigma$ error bounds assuming a $\mathrm{v}_{\mathrm{p}}$ of $1.75 \mathrm{~km} / \mathrm{s}$

We also compare our result to constraints from the subbottom profiler and International Ocean Drilling Project (IODP). Sub-bottom profiler data was only available at a few stations, but at station L13D the two-way travel time was $0.035 \mathrm{~s}$ corresponding to a sedimentary thickness of about $54-64 \mathrm{~m}$ for $v_{p}$ of $1.55-1.84 \mathrm{~km} / \mathrm{s}$, in good 
(j)

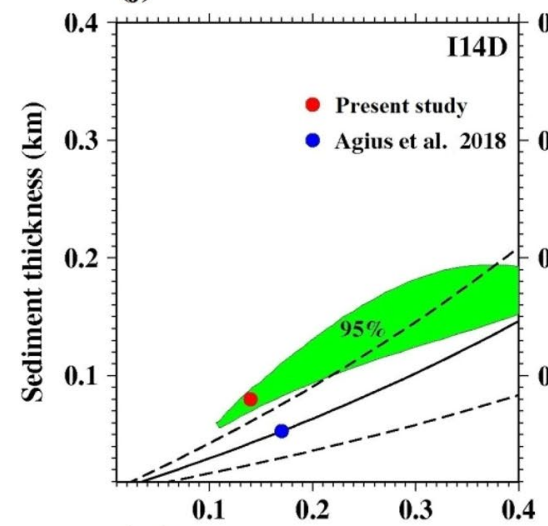

(m)

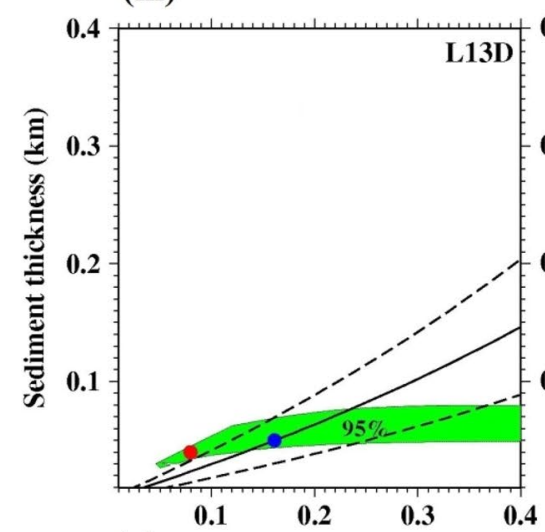

(p)

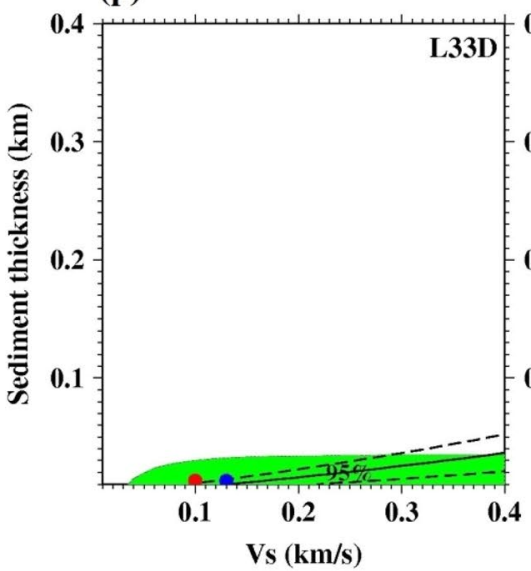

(k)

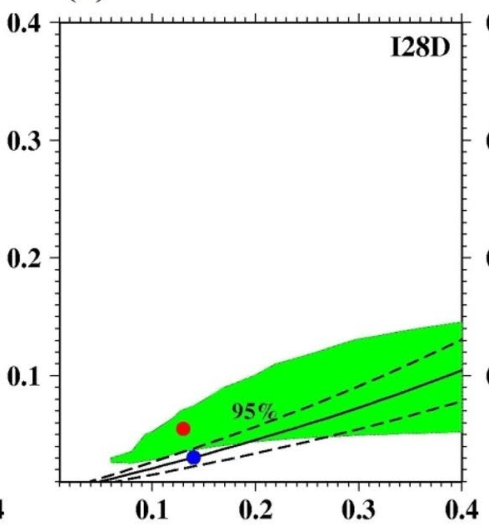

(n)

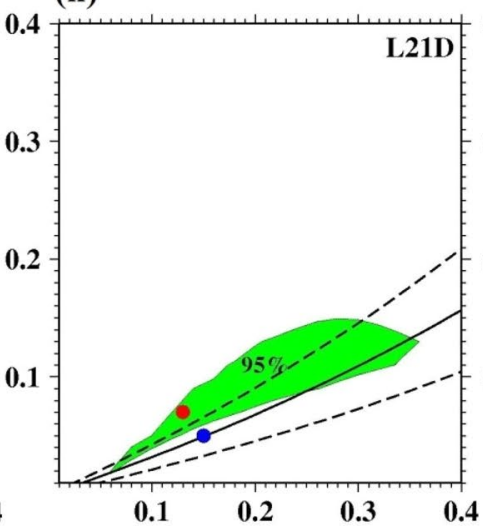

(q)

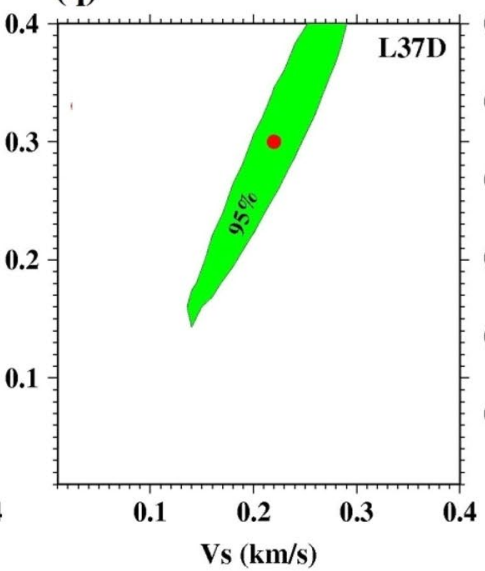

(l)

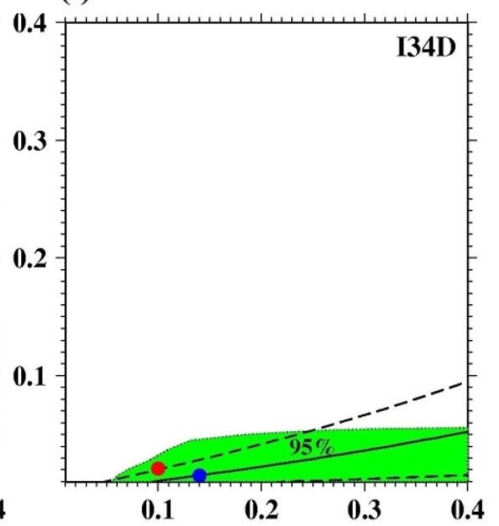

(o)

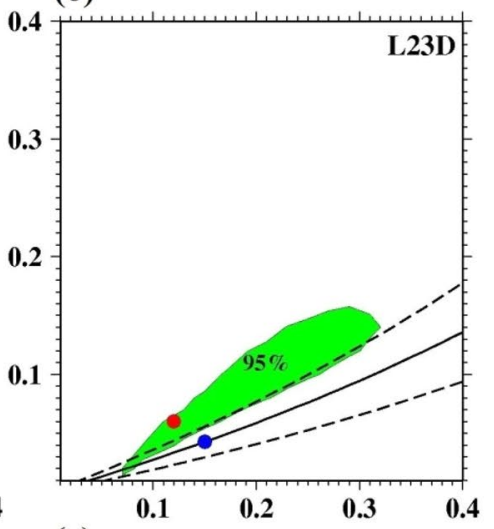

(r)

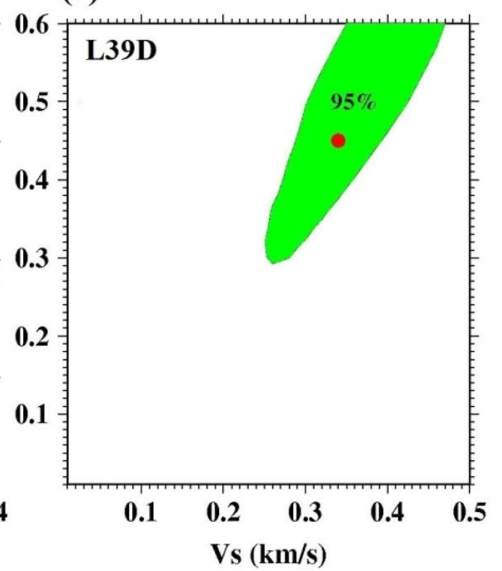

Fig. 3 (continued)

agreement with our result $(40 \pm 10 \mathrm{~m})$ (Agius et al. 2018). The IODP cores were drilled on the eastern side of the ridge in seafloor 3.7 Myr old, about 65 and $84 \mathrm{~km}$ away from the S11D station. The IODP cores found $200 \mathrm{~m}$ sediment thickness in a local sedimentary basin (Ruddiman and Janecek 1989), which is much thicker than most of the stations in the present study and other studies (Aguis et al. 2018; Straume et al. 2019). This is probably explained by the fact that sediment deposition is enhanced by gravity flows and mass wasting in local basins (Ruddiman and Janecek 1989). IODP preferentially samples basins, while we preferentially chose station locations at bathymetric highs, given the advantage for instrument recovery. The larger $110 \pm 20 \mathrm{~m}$ sediment thickness result at one of our stations, S26D, is likely explained by its location in a flat bottomed local basin. This suggests that even though the sediment is thin across most of the region, there is likely significant local variation by up to $\sim 100 \mathrm{~m}$ 


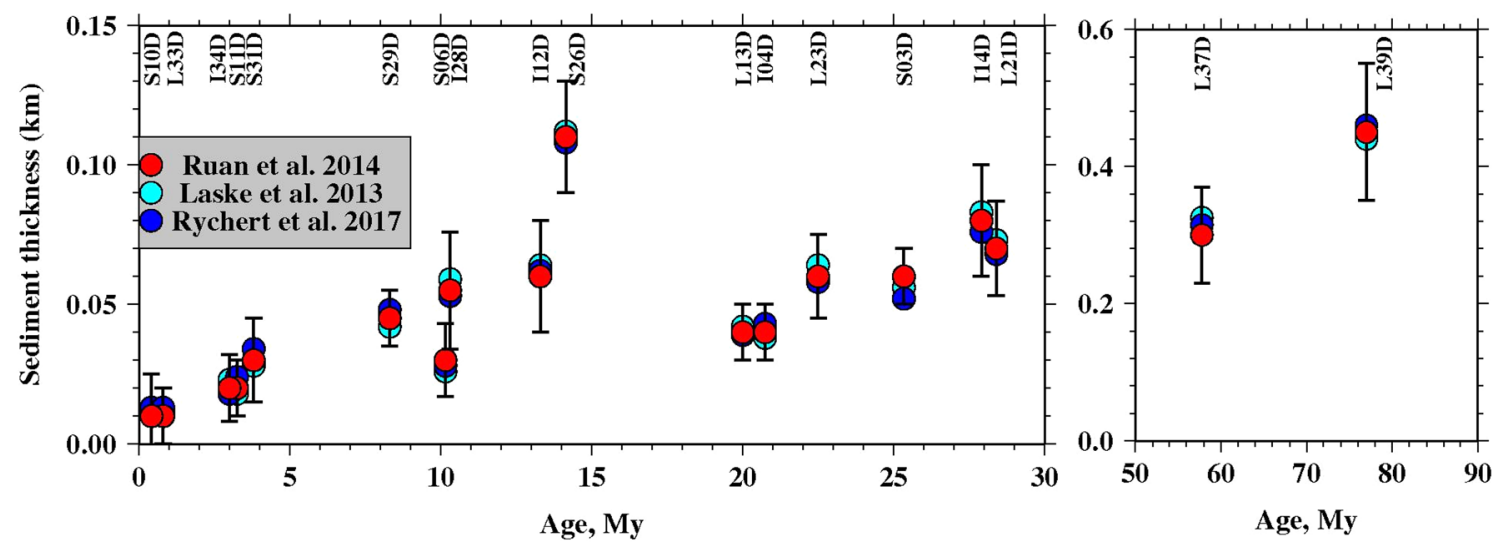

Fig. 4 Effect of sediment thickness using different velocity models. Red circles define the values obtained from the model of Ruan et al. (2014), while cyan and blue circles show the value obtained from
Crust.1 (Laske et al. 2013) model and the velocity model of Rychert et al. (2017), respectively
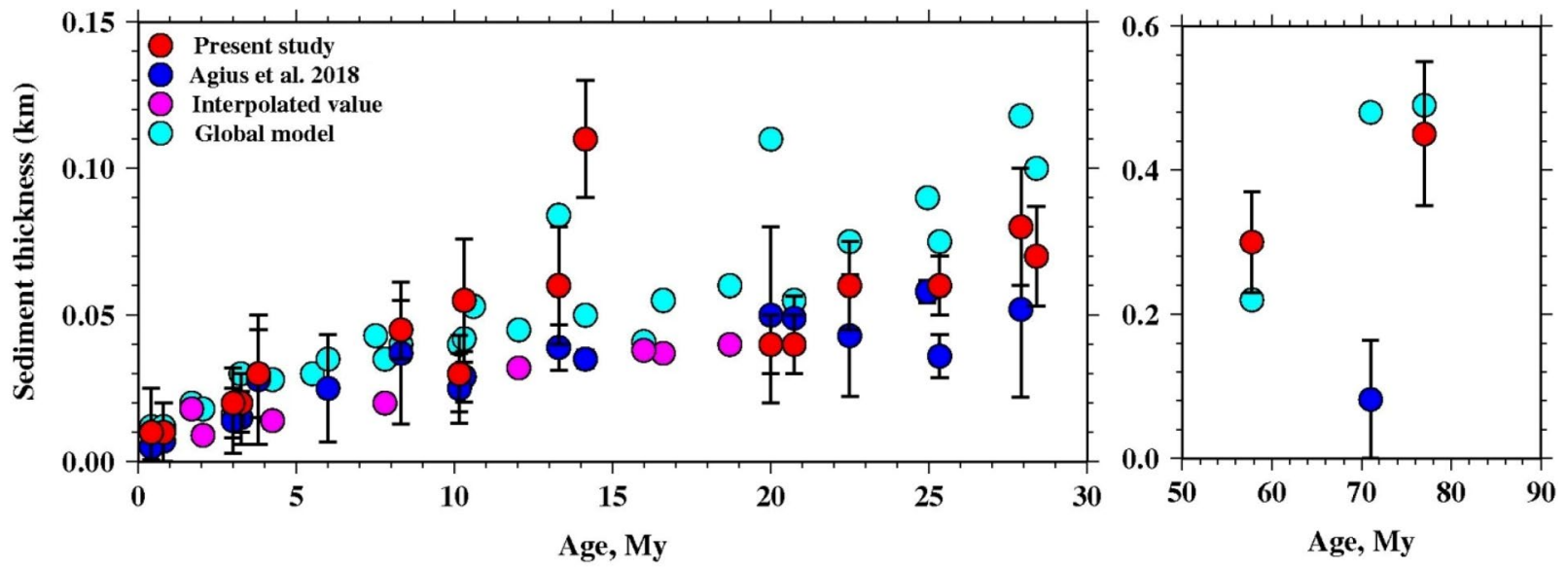

Fig. 5 Variation of sediment thickness with seafloor age. Red circles show the results of present study, while cyan and blue circles show the global model and Ps result (Agius et al. 2018), respectively. The magenta circles show the locations where the Ps study did not resolve

due to local sedimentary processes in addition to pelagic sedimentation.

We compare our shear wave speed vs the inferred thickness of the sediment layer to that from Cascadia (Ruan et al. 2014) (Fig. 6). The sediments are much thicker beneath Cascadia than our study region so we couldn't compare the results from both studies at less than $\sim 85$ m thickness. At 85-140 m thickness, we have only one measurement which shows higher shear velocity than the Cascadia result but within the error bounds. At sediment thicknesses $>200 \mathrm{~m}$, our sediment thickness and shear velocity estimates are within error of the Cascadia results but slightly slower.

We also inverted for a continuous shear velocity, $\mathrm{v}_{\mathrm{S}}$, structure as a function of depth after Ruan et al. (2014); Bell et al. (2015) using an equation of the form: sediment characteristics, but reported values based on interpolation based on nearby stations. $95 \%$ confidence limits are shown by black error bars

$V_{s}(z)=\frac{a z^{2}+b z+c V_{0}}{(z+c)}$

where $\mathrm{V}_{0}$ is $100 \mathrm{~m} / \mathrm{s}$ after Ruan et al. (2014). We solve for coefficients $\mathrm{a}, \mathrm{b}$ and $\mathrm{c}$ using an iterative damped least squares inversion using admittance observations for all stations with an initial estimate of $100 \mathrm{~m}$ or more of sediment thickness, assuming the crustal structure given in Table 1. We found that using stations with thinner grid search sediment estimates were not resolvable and destabilized the inversion. We find values for the coefficients of $a=0.09 \pm 0.26$, $b=1.13 \pm 0.22$, and $c=0.65 \pm 0.20$, and our shear velocity function is plotted relative to the Bell et al. (2015) curve in Fig. 7. Our velocity profile is slower than the Bell et al. (2015) curve, although our coefficients are within the error 


\section{Shear wavespeed $(\mathrm{km} / \mathrm{s})$}

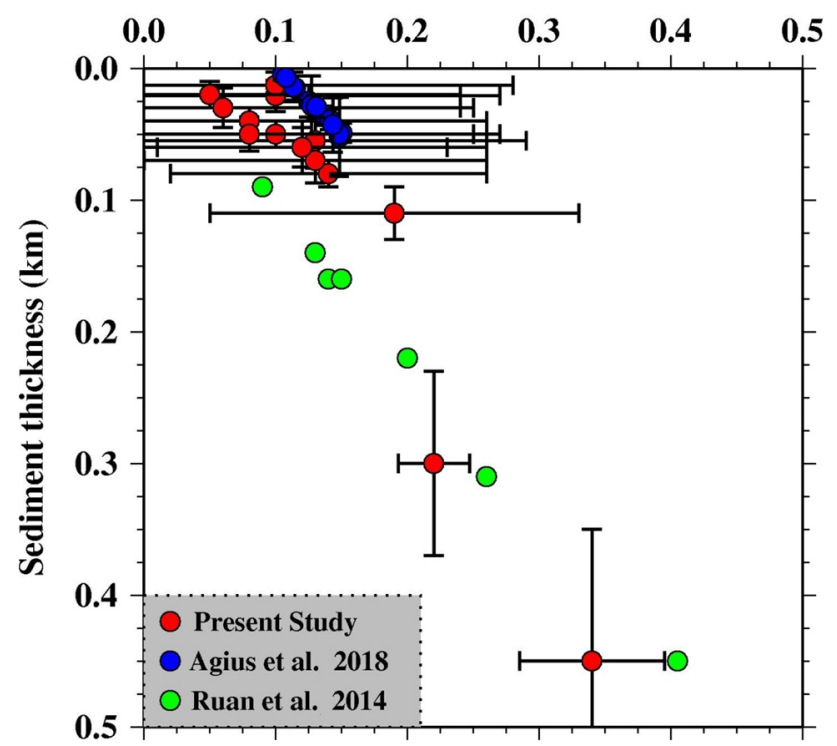

Fig. 6 Variation of shear wave velocity with respect to sediment thickness. The red circles show the result of present study. The blue circles show the Ps result from our study area (Agius et al. 2018). The green circles show the Ruan et al. (2014) results from the Juan de Fuca plate. 95\% confidence limits are shown as the black error bars

of the Bell et al. (2015) coefficients. Using our new relationship, the sediment thickness estimates for the stations used in the inversion increase to $782 \pm 235 \mathrm{~m}$ for L37D,
$759 \pm 225 \mathrm{~m}$ for $\mathrm{L} 39 \mathrm{D}$ and $222 \pm 204 \mathrm{~m}$ for S26D, but are within the reported error bounds for the single layer thickness reported in Table 2 . The slower velocities could reflect different sediment properties in the Atlantic in comparison to the Pacific.

\section{Conclusion}

We determine the sediment thickness at the Equatorial MidAtlantic Ridge using the admittance function obtained for microseism-generated Rayleigh wave. The estimated sediment thickness varies from 10 to $450 \mathrm{~m}$. It is $10-20 \mathrm{~m}$ thick at the ridge and it reaches up-to $400-450 \mathrm{~m}$ on the seafloor older than 70 Myr. For young seafloor $(<10 \mathrm{My})$ our estimated thicknesses are consistent with those from a previous study that used Ps conversions and also the global model (Agius et al. 2018; Straume et al. 2019). For the moderate aged lithosphere (17-30 Myr), the best fitting sediment thickness is $25-30 \mathrm{~m}$ thinner than the global model, but 5-25 $\mathrm{m}$ thicker than the thicknesses based on Ps delay times. For the oldest ages (50-80 My) sediment thickness are similar to the global model. Overlap of the $95 \%$ confidence regions between the admittance function and Ps estimates for thickness and shear velocity is found at 15 out of 16 stations where both methods yielded results. It suggests that both methods determine accurate estimates for sediment thickness. In addition, using admittance can expand the
Fig. 7 Our sediment velocitydepth relationship (solid) in comparison to that of Bell et al. (2015) (dashed)

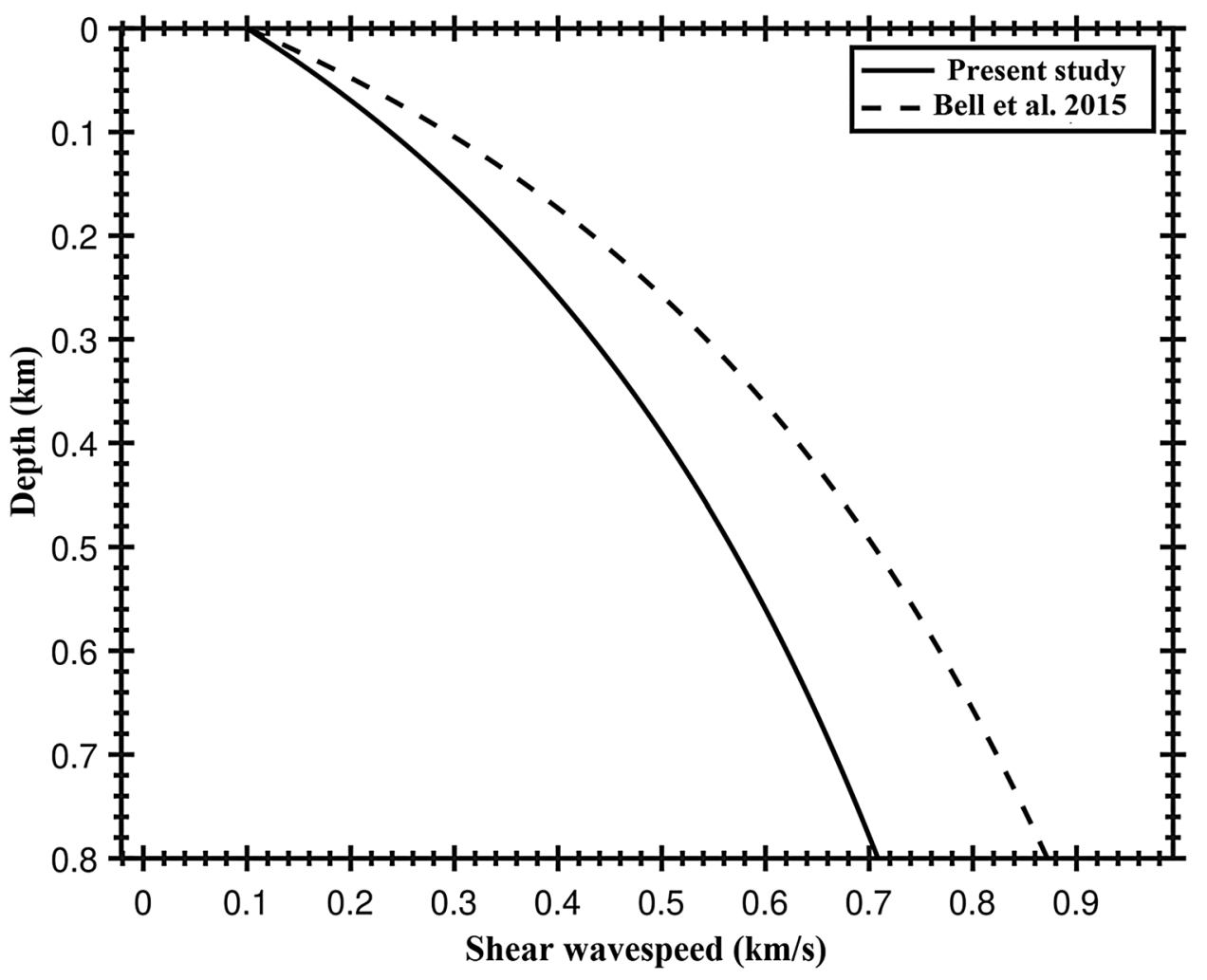


numbers of resolved station, in particular in locations where Ps phases could not determine sediment structure.

Acknowledgements We acknowledge funding from the Natural Environment Research Council (NE/M003507/1 and NE/K010654/1) and the European Research Council (GA 638665). Ocean bottom seismometers were provided by Scripps Institution of Oceanography, LamontDoherty Earth Observatory, and the Institute de Physique du Globe de Paris. We would like to thank the crew aboard the ships RV Marcus G Langseth (MGL02-16) and the RRS Discovery (DY072). We thank Prof. Wu-Cheng Chi, Editor, and the three reviewers for their critical comment and suggestions that helped improving the manuscript. All the figures were generated using Generic Mapping Tools v.4.5.0 (www. soest.hawaii.edu/gmt, last accessed December 2014). Data are available from the Iris DMC website: https://ds.iris.edu/ds/nodes/dmc/

Open Access This article is licensed under a Creative Commons Attribution 4.0 International License, which permits use, sharing, adaptation, distribution and reproduction in any medium or format, as long as you give appropriate credit to the original author(s) and the source, provide a link to the Creative Commons licence, and indicate if changes were made. The images or other third party material in this article are included in the article's Creative Commons licence, unless indicated otherwise in a credit line to the material. If material is not included in the article's Creative Commons licence and your intended use is not permitted by statutory regulation or exceeds the permitted use, you will need to obtain permission directly from the copyright holder. To view a copy of this licence, visit http://creativecommons.org/licenses/by/4.0/.

\section{References}

Agius MR, Harmon N, Rychert CA, Tharimena S, Kendall JM (2018) Sediment characterization at the equatorial Mid-Atlantic Ridge from P-to-S teleseismic phase conversions recorded on the PILAB experiment. Geophys Res Lett 45(22):12-244

Bell SW, Ruan Y, Forsyth DW (2015) Shear velocity structure of abyssal plain sediments in Cascadia. Seismol Res Lett 86:1247-1252

Berge PA, Mallick S, Fryer GJ, Bartow N, Carter JA, Sutton GH, Ewing JI (1991) In situ measurements of transverse isotropy in shallow-water marine sediments. Geophys J Int 104:241-254

Crawford WC, Webb SC (2000) Identifying and removing tilt noise from low-frequency $(\% 3 \mathrm{c} 0.1 \mathrm{~Hz})$ seafloor vertical seismic data. Bull Seismol Soc Am 90:952-963

Crawford WC, Webb SC, Hildebrand JA (1991) Seafloor compliance observed by long-period pressure and displacement. J Geophys Res 96(B10):16151-16160

Doran AK, Laske G (2019) Seismic structure of marine sediments and upper oceanic crust surrounding Hawaii. J Geophys Res 124:2038-2056

Dorman LM, Jacobson RS (1981) Linear inversion of body wave data-Part 1: velocity structure from travel times and ranges. Geophysics 46:138-151

Draper NR, Smith H (1998) Applied regression analysis. Wiley Series in probability and Statistics, New Jersey
Essen H-H, Grevemeyer I, Herber R, Weigel W (1998) Shear wave velocity in marine sediments on young oceanic crust: constraints from dispersion analysis of Scholte waves. Geophys J Int 132:227-234

Harmon N, Forsyth DW, Lamm R, Webb SC (2007) P and S wave delays beneath intraplate volcanic ridges and gravity lineations near the East Pacific Rise. J Geophys Res 112:1-12

Harmon N, Rychert CA, Agius MR, Tharimena S, Le Bas T, Kendall JM, Constable S (2018) Marine geophysical investigation of the chain fracture zone in the Equatorial Atlantic from the PI-LAB experiment. J Geophys Res 123(12):11-016

Herrmann RB (1978) Computer programs in earthquake seismology, Volume 1: general programs (NTIS PB 292 462). Herrmann RB (ed), Department of Earth and Atmospheric Sciences. Saint Louis Univ, Saint Louis.

Laske G, Masters G, Ma Z, Pasyanos M (2013) Update on CRUST1.0_ A 1-degree global model of earth's crust. Geophys Res Abstract 15, EGU2013-2658.

Lewis BTR, Dorman LM (1998) Recording teleseisms on the seafloor: an example from the Juan de Fuca plate. Bull Seismol Soc Am $88: 107-116$

Muller RD, Sdrolias M, Gaina C, Roest WR (2008) Age, spreading rates, and spreading asymmetry of the world's ocean crust. Geochem Geophys Geosyst 9(4):1-19

Olson P, Reynolds E, Hinnov L, Goswami A (2016) Variation of ocean sediment thickness with crustal age. Geochem Geophys Geosyst 17:1349-1369

Ruan Y, Forsyth D, Bell S (2014) Marine sediment shear velocity structure from the ratio of displacement to pressure of Rayleigh waves at seafloor. J Geophys Res 119:6357-6371. https://doi. org/10.1002/2014JB011162

Ruddiman W, Janecek T (1989) Pliocene-pleistocene biogenic and terrigenous fluxes at equatorial Atlantic sites 662, 663, and 664. Proc Ocean Drill Program Sci Results 108(21):211-240. https://doi. org/10.2973/odp.proc.sr.108.165.1989

Rychert CA, Harmon N, Kendall JM, Agius MR, Tharimena S (2017) Surface wave imaging of the Lithosphere-Asthenosphere system beneath 0-80 My seafloor of the equatorial Mid-Atlantic Ridge from the PI-LAB Experiment. AGU-Abstract.

Rychert CA, Harmon N, Tharimena S (2018) Scattered wave imaging of the oceanic plate in Cascadia. Sci Adv. https://doi.org/10.1126/ sciadv.aao1908

Sclater JG (2003) Ins and outs on the ocean floor. Nature 421:590-591

Straume EO, Gaina C, Medvedev S, Hochmuth K, Gohl K, Whittaker JM (2019) GlobSed: updated total sediment thickness in the world's oceans. Geochem Geophys Geosyst 20:1756-1772

Webb SC, Zhang X, Crawford W (1991) Infragravity waves in the deep ocean. J Geophys Res 96:2723-2736

Zha Y, Webb SC (2016) Crustal shear velocity structure in the Southern Lau Basin constrained by seafloor compliance. J Geophys Res 121:3220-3237

Publisher's Note Springer Nature remains neutral with regard to jurisdictional claims in published maps and institutional affiliations. 